\title{
Endovascular management of fusiform aneurysms in the posterior circulation: the era of flow diversion
}

\author{
Ahmed J. Awad, MD, ${ }^{1,2}$ Justin R. Mascitelli, MD, ${ }^{1}$ Reham R. Haroun, MD, ${ }^{1}$ Reade A. De Leacy, MD, ${ }^{1}$ \\ Johanna T. Fifi, MD, ${ }^{1}$ and J Mocco, MD, MS ${ }^{1}$ \\ 'Department of Neurological Surgery, Icahn School of Medicine at Mount Sinai, Mount Sinai Health System, New York, New \\ York; and ${ }^{2}$ Department of Neurosurgery, Medical College of Wisconsin, Milwaukee, Wisconsin
}

\begin{abstract}
Fusiform aneurysms are uncommon compared with their saccular counterparts, yet they remain very challenging to treat and are associated with high rates of rebleeding and morbidity. Lack of a true aneurysm neck renders simple clip reconstruction or coil embolization usually impossible, and more advanced techniques are required, including bypass, stent-assisted coiling, and, more recently, flow diversion. In this article, the authors review posterior circulation fusiform aneurysms, including pathogenesis, natural history, and endovascular treatment, including the role of flow diversion. In addition, the authors propose an algorithm for treatment based on their practice.
\end{abstract}

https://thejns.org/doi/abs/10.3171/2017.3.FOCUS1748

KEY WORDS fusiform; Pipeline; stroke; embolization; coil; bypass

$\mathrm{F}$ USIFORM aneurysms are defined as circumferential dilations of an intracranial artery without an ostium or neck. ${ }^{12}$ They are commonly located in the posterior circulation, especially the vertebral artery (VA), basilar artery (BA), and posterior cerebral artery (PCA). ${ }^{11}$ Fusiform aneurysms are uncommon compared with their saccular counterparts, yet they remain very challenging to treat. The first case of a vertebral fusiform aneurysm was described by Wells in 1922, ${ }^{35}$ and since then several terms have also been used, including dolichoectatic aneurysm, transitional aneurysm, and giant serpentine aneurysm.

Posterior circulation fusiform aneurysms (PCFAs) have a significant male predominance (approximately 70\%) and most commonly present as posterior circulation ischemic stroke. ${ }^{12,31}$ In addition, they may cause cranial nerve palsies, brainstem compression, and subarachnoid hemorrhage (SAH). Contrary to the more common saccular aneurysms, fusiform aneurysms are associated with high rates of rebleeding and morbidity.

In this article, we review PCFAs, including pathogenesis, natural history, cerebrovascular surgical treatment, and endovascular treatment, including the role of flow diversion. In addition, we propose an algorithm for treatment based on our practice.

\section{Pathogenesis and Natural History}

Fusiform aneurysms may occur due to a variety of underlying pathologies affecting the wall of the blood vessel. The most common proposed causes are dissection and atherosclerosis. ${ }^{6,730}$ Our understanding of the natural history of PCFAs is very limited and largely depends on the presenting signs and symptoms. Symptomatic patients have a poor natural history if they do not undergo treatment, especially if they present with brainstem ischemia or compression. In patients with ruptured aneurysms, the rebleeding rate is high and ranges between $30 \%$ and $85 \% .^{1,23}$ The mortality rate is also high for untreated ruptured aneurysms. In a study that evaluated conservative management in ruptured PCFAs, the mortality rate was 38\% after a mean follow-up period of 18 months..$^{10}$

In a prospective study of vertebrobasilar aneurysms over a 12-year period at the Mayo Clinic, the annual rupture rate of fusiform aneurysms was $2.3 \% .^{13,21}$ The initial diameter of an aneurysm is a significant predictor of lesion rupture. The authors also found that an initial diameter larger than $10 \mathrm{~mm}$ in fusiform aneurysms was a significant risk factor for aneurysm enlargement and future rupture. The mortality rate was approximately 6 times higher in

ABBREVIATIONS AICA = anterior inferior cerebellar artery; $\mathrm{BA}=$ basilar artery; $\mathrm{EC}-\mathrm{IC}=$ extracranial-intracranial; IEL = internal elastic lamina; $\mathrm{MRA}=\mathrm{MR}$ angiography; $\mathrm{PCA}=$ posterior cerebral artery; PCFA = posterior circulation fusiform aneurysm; $\mathrm{PED}=$ Pipeline embolization device; $\mathrm{PICA}=$ posterior inferior cerebellar artery; $\mathrm{SAC}=$ stent-assisted coiling; SAH = subarachnoid hemorrhage; SCA = superior cerebellar artery; STA = superficial temporal artery; VA = vertebral artery.

SUBMITTED February 6, 2017. ACCEPTED March 20, 2017.

INCLUDE WHEN CITING DOI: 10.3171/2017.3.FOCUS1748. 
patients with aneurysm growth than in those with no enlargement. ${ }^{21}$

Therefore, based on observations of the natural history, the vast majority of ruptured PCFAs should be treated. Additionally, unruptured PCFAs larger than $10 \mathrm{~mm}$ also likely warrant treatment.

\section{Classification}

There are 2 widely accepted classification systems for nonsaccular aneurysms, including the fusiform type, that stratify patients into risk groups. Flemming's classification for nonsaccular vertebrobasilar circulation aneurysms is based on radiographic appearance. ${ }^{12}$ Lesions are defined as having an arterial dilation greater than 1.5 times the normal diameter without any neck (Huber's definition), and the types are as follows: A) fusiform (14\%), aneurysmal dilation of the vessel without an identifiable neck involving a portion of arterial segment; B) dolichoectasia (45\%), uniformed dilation involving the entire artery with any degree of tortuosity; C) transitional (19\%), uniform aneurysmal dilation of the artery with superimposed dilation of a portion of the involved arterial segment; and the indeterminate type (20\%). Fusiform and transitional types are most likely to be symptomatic, while the dolichoectatic type has a more benign nature. Acute dissecting aneurysms were excluded because of the known distinctive behavior.

The other classification system is that of Mizutani et al. and consists of 4 types based on histopathology. ${ }^{24}$ Type I, classic dissecting aneurysm characterized by widespread disruption of the internal elastic lamina (IEL) without intimal thickening. This type typically presents with SAH and high rates of rebleeding. Type II, segmental ectasia, with a more benign clinical course than Type I. This type is characterized by extended and/or fragmented IEL with intimal thickening. In addition, the luminal surface is smooth without thrombus formation. Type III, dolichoectatic dissecting aneurysm. This type is distinguished pathologically from Type II by dissections in the thickened intima and organized luminal thrombus. Most Type III aneurysms are symptomatic, grow over time, and are frequently associated with hemorrhage and a mortality rate of $50 \%$. Lastly, Type IV is saccular aneurysm characterized by minimally disrupted IEL without intimal thickening and is associated with a high risk of rupture.

\section{Treatment}

\section{Choice of Treatment}

All fusiform aneurysms have been historically treated with different open surgical treatment modalities, including Hunterian ligation, trapping, surgical bypass, and clip reconstruction techniques. ${ }^{31}$ However, endovascular therapy has emerged as the primary treatment modality for PCFAs over the past decade. Recently, endovascular treatments have been successfully used in treating PCFAs with good outcomes. In fact, microsurgical treatment is generally reserved for cases that cannot be treated with endovascular therapy. The endovascular options include parent vessel coil occlusion, stenting alone, stent-assisted coiling (SAC), and flow-diverting stents (Fig. 1).

\section{Microsurgical Management}

Open surgical treatment of PCFAs is becoming a less popular option given the recent advancements in endovascular therapy. Microsurgical treatment modalities often involve flow reduction or bypass/trapping in cases of poor collateral supply, flow reversal in cases of adequate collateral supply, or trapping with aneurysm decompression for lesions with mass effect. Since fusiform aneurysms do not have a true neck, they are usually not amenable to clip reconstruction techniques. Additionally, it is not uncommon for PCFAs to be partially calcified and/or thrombosed, further complicating the open surgical approach. Hence, trapping with or without bypass is considered the main microvascular modality.

Drake and colleagues published extensively on their operative experience with fusiform aneurysms in the posterior circulation. ${ }^{8,9,33}$ The authors used different modalities based on patient presentation, clinical status, and collateral supply. Outcomes were almost comparable between the different modalities, with approximately $70 \%$ of treated patients achieving good to excellent outcomes.

Kalani et al. ${ }^{16}$ reported the most recent experience at the Barrow Neurological Institute with giant aneurysms in the posterior circulation. The 12-aneurysm cohort included 8 fusiform aneurysms. The primary treatment modality was extracranial-intracranial (EC-IC) bypass. Superficial temporal artery-superior cerebellar artery (STA-SCA) bypasses were performed in 7 cases and STA-PCA was performed in 1 case. Flow was reserved or reduced by complete $(n=6)$ or partial $(n=1)$ occlusion of the BA, or by occlusion of the VA distal to the posterior inferior cerebellar artery (PICA) $(n=1)$. Recurrence and complications were high and the mortality rate among fusiform aneurysms was approximately 40\%. The authors did admit that despite their aggressive surgical approach, the long-term outcome was poor for most patients.

More recently, Lawton et al. published an evolved technique of surgical bypass for treating fusiform aneurysms in the basilar trunk. ${ }^{19}$ The study included 37 patients, and the bypass evolved in 3 distinct phases, each with different hemodynamic alternations. Surgical bypasses consisted of EC-IC (STA-SCA and STA-PCA) bypasses in Phase 1 for flow reversal, IC-IC (VA-SCA) bypasses in Phase 2 for flow reduction, and Phase 3 (middle cerebral arteryPCA) for distal occlusion. Phase 1 led to extensive flow reduction that prompted $\mathrm{BA}$ thrombosis and was associated with $100 \%$ mortality. On the other hand, Phase 2 was safer (67\% mortality rate) but did not prevent aneurysm growth or progression of symptoms. As a result, the authors revised their technique to distal occlusion, achieving an improved surgical outcome and aneurysm stabilization with a better mortality rate $(62 \%)$. However, this technique reduced the flow to brainstem perforators causing ischemic damage, despite treatment with antiplatelet agents.

\section{Endovascular Management}

The lack of a true aneurysm neck usually makes simple coil embolization impossible and more advanced techniques are required, including SAC and, more recently, flow diversion (Figs. 2 and 3). Parent vessel occlusion is a 


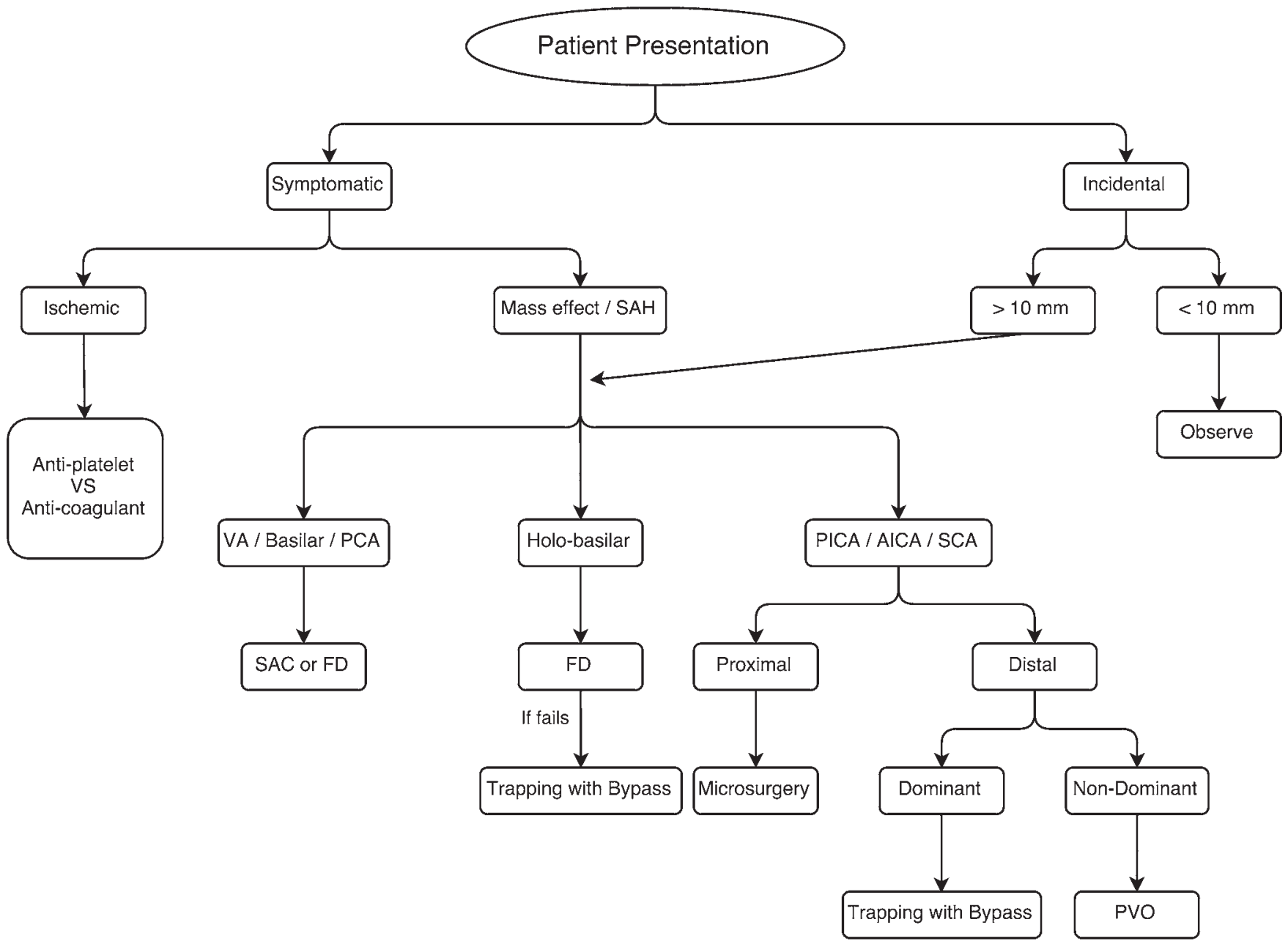

FIG. 1. Suggested treatment algorithm for fusiform aneurysms in the posterior circulation based on presentation. FD = flow diverter; PVO = parent vessel occlusion.

reasonable option for nondominant VA aneurysms as well as distal aneurysms of the nondominant PICA, anterior inferior cerebellar artery (AICA), or SCA.

Higashida et al. ${ }^{15}$ reported the first case of SAC in PCFAs. They used an intravascular stent in conjunction with Guglielmi detachable coils in a ruptured fusiform aneurysm in the BA. Since then, several case series have been published regarding the use of SAC in the treatment of PCFAs. ${ }^{6,29,34}$ Interestingly, it appears that certain locations of fusiform aneurysms in the PCA have distinct entities with different outcomes. In the 14-year Stanford experience of treating PCFAs, ${ }^{6}$ Steinberg et al ${ }^{33}$ reported that PCA aneurysms had the best outcome (90\%), followed by VA and PICA aneurysms (60\%); aneurysms located in the BA and vertebrobasilar junction had the worst outcome (39\%).

Initial experience with flow diversion in PCFAs was mixed with poor outcomes. ${ }^{32}$ However, when used in carefully selected patients, PCFAs have been recently reported to have a good to excellent outcome in the majority of those patients. Table 1 summarizes large series ( $>5$ cases) on the use of flow diverters for PCFAs.

Byrne and colleagues published their initial experience with Silk (Balt Extrusion) flow diverters in the treatment of intracranial aneurysms in a multicenter prospective study. ${ }^{4}$ Of 70 patients, there were 11 cases of PCFAs. Of these patients, 2 patients died, and there were 2 devicerelated complications. There were no available data on postoperative angiographic obliteration.

In 2014, both Thomas Jefferson University and Rush University groups published their experience with the Pipeline embolization device (PED; Medtronic) for fusiform aneurysms in the posterior circulation..$^{25,26}$ These reports included 7 and 12 cases of PCFAs, respectively. The device-related complication rate was approximately $25 \%$, and $70 \%-90 \%$ of patients had good to excellent neurological outcome. During angiographic follow-up, complete occlusion varied significantly between the 2 studies, ranging between $30 \%{ }^{25}$ and $75 \% .^{26}$

Contrary to their initial experience with poor outcomes,$^{32}$ a team from the University at Buffalo reported excellent results in their latest experience with PED for PCFAs. ${ }^{27}$ Eleven (90\%) of 12 patients recovered to a modified Rankin Scale score of 0 or 1 after a clinical follow-up duration of 22 months, with only 1 patient experiencing a perforator territory infarction with poor clinical outcome 


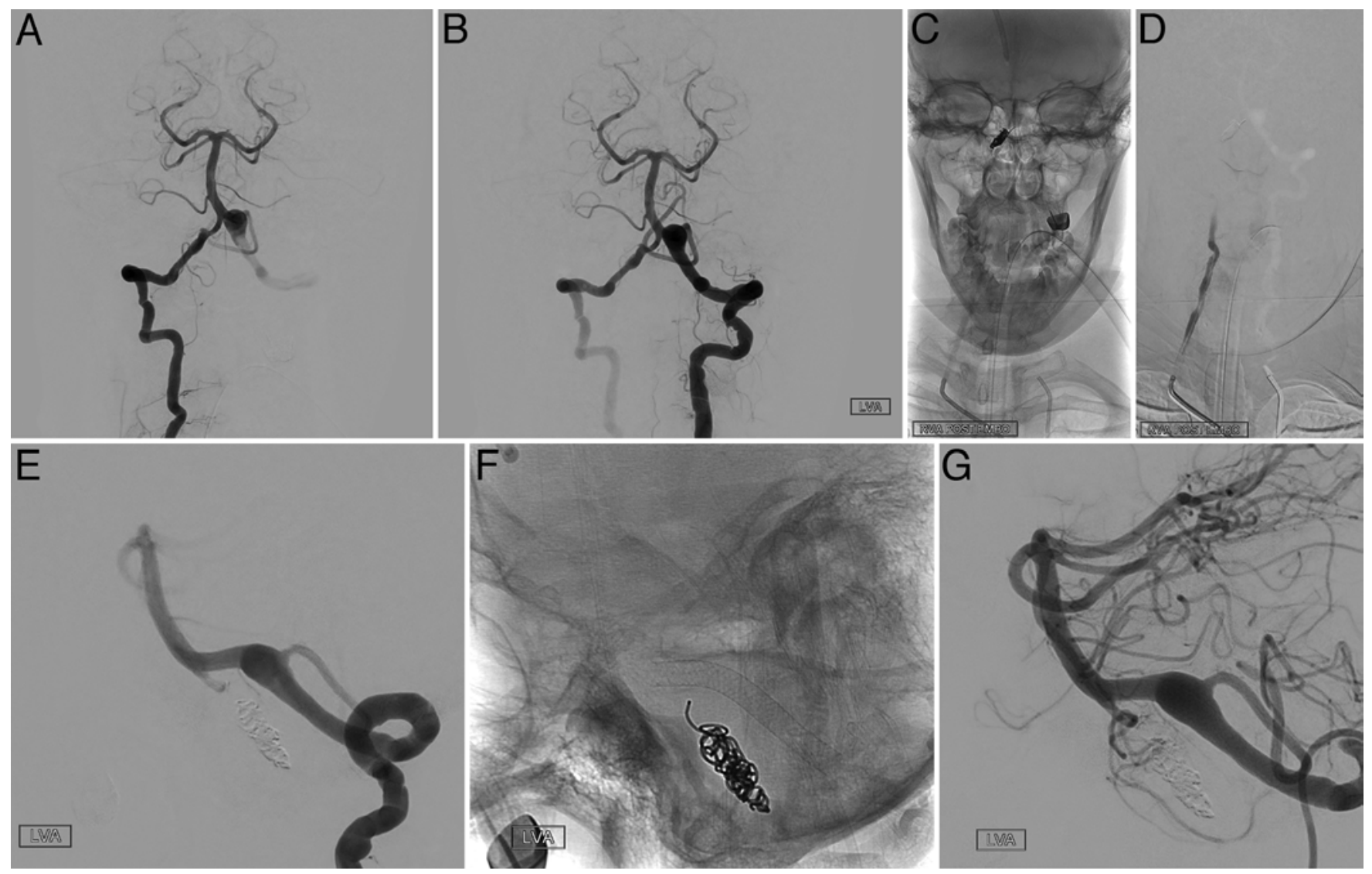

FIG. 2. Angiograms obtained in a 46-year-old woman with a good-grade SAH. A and B: Initial digital subtraction (DS) angiograms (right VA injection $[\mathrm{A}]$ and left VA injection $[\mathrm{B}]$ ) demonstrating bilateral fusiform VA aneurysms, of which the right-sided aneurysm appeared irregular and the likely source of SAH. C and D: The patient was treated acutely with coil occlusion of the right VA (right vertebral injection, unsubtracted $[C]$ and subtracted $[D]$ views). Given that the right VA aneurysm was the likely source of $S A H$, the patient was acutely allowed to recover from her SAH. E-G: The fusiform left VA aneurysm (left VA DS angiogram lateral view $[E]$ ) was treated with flow diversion a few weeks later (left VA injection, unsubtracted [F] and subtracted [G] views). The patient will undergo delayed angiography to evaluate for aneurysm occlusion and vessel remodeling.

(modified Rankin Scale Score 4). At last follow-up, the complete occlusion rate was $100 \%$, and the PEDs were patent. The authors attributed the dramatic improvement in outcomes to careful patient selection. All patients presented early, and none had evidence of stroke on MRI before treatment. The second factor was the strict dual antiplatelet regimen with confirmation of the therapeutic effect of antiplatelet therapy by using response testing before flow diversion. Technically, the authors used fewer but longer $(35 \mathrm{~mm})$ PEDs compared with more and shorter $(20 \mathrm{~mm})$ devices in their initial report. In addition, the new experience included adjunctive coiling, which might reduce stent prolapse by acting as a scaffold.

More recently, Bhogal and his colleagues from Germany published the largest series of flow diversion in PCFAs. ${ }^{2}$ Of the 56 patients with nonsaccular aneurysms, there were 24 fusiform aneurysms. The study used 2 types of flow-deverter devices: PED and p64 flow modulation device (Phenox). The mortality rate was low, with only 1 death (4\%). The complete aneurysm occlusion rate was $75 \%$ with minor residual filling seen in $12.5 \%$ of cases and an unchanged appearance in 1 patient (4\%). In the 4 patients without angiographic occlusion, the aneurysm de- creased in maximum diameter, with increased intraaneurysmal thrombus in 3 cases (75\%) on MRI follow-up.

\section{The Fate of Covered Branch Vessels With Flow Diverters}

The location of aneurysms in the distal VA $\left(\mathrm{V}_{4}\right)$ and vertebrobasilar junction in relation to the branch vessels, especially PICA and AICA, often requires covering the arterial ostium, theoretically increasing the risk of branch vessel occlusion and infarction. A meta-analysis published in 2013 showed that the rate of perforator infarction is 3\% with significantly higher odds in posterior circulation aneurysms. ${ }^{3}$

Initial experiences with flow diverters have shown mixed results regarding the fate of covered branch vessels, ranging between complete patency on all follow-up studies to immediate occlusion after flow-diverter deployment or shortly after. ${ }^{5,17,18,28,36}$ However, recent experiences reported a $0 \%$ rate of branch occlusion in the posterior circulation on immediate or follow-up angiography. . $^{1420,22}$ Mazur and colleagues' series specifically reported the patency of PICA and aneurysm occlusion on angiography. ${ }^{22}$ This series of 11 aneurysms located predominantly in the 

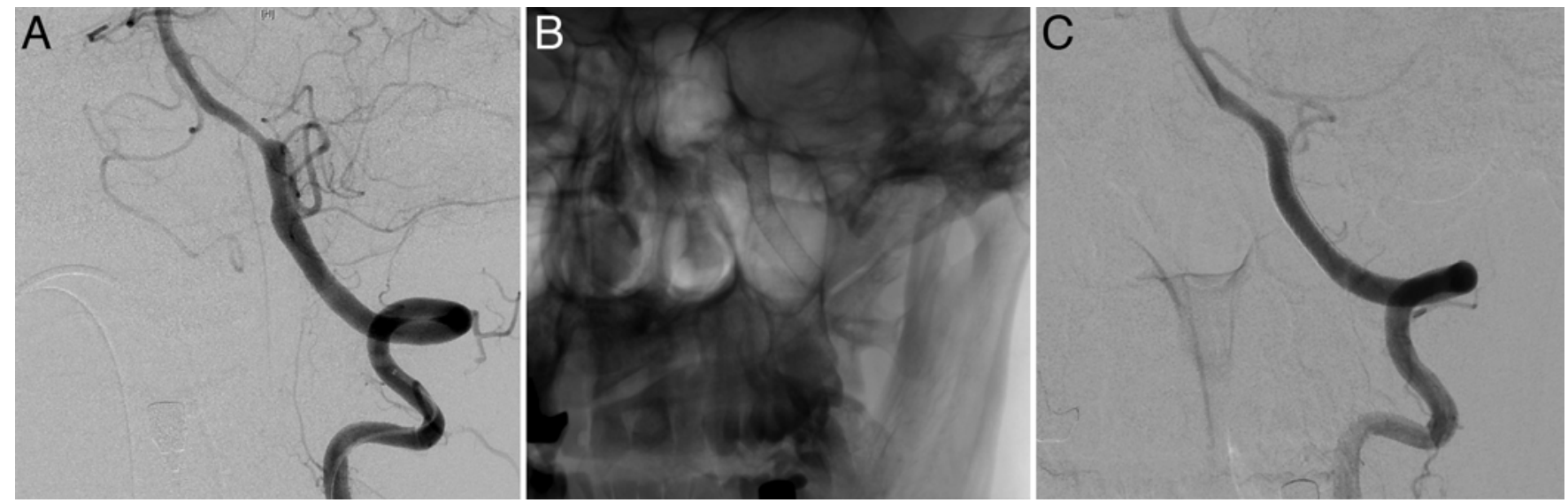

FIG. 3. Angiograms obtained in a 57-year-old man who presented with poor-grade SAH. A: Initial DS angiogram (left VA injection) demonstrated a single fusiform aneurysm involving the left VA and encompassing the origin of the PICA. B: Given the nature of the aneurysm, flow diversion was thought to be the only treatment option that could exclude the aneurysm. Therefore, the patient received dual antiplatelet therapy (aspirin and Plavix), and a flow diverter was placed in the left VA (left VA injection, unsubtracted view). The patient required ventriculoperitoneal shunting, for which Plavix was discontinued. C: Delayed DS angiogram demonstrated complete aneurysm occlusion and arterial remodeling (left VA injection).

VA included fusiform aneurysms (80\%). The flow diverter spanned the PICA ostium in all cases, with 1 patient experiencing an occluded PICA and in-stent stenosis on immediate angiography. The in-stent stenosis was resolved after abciximab administration, and the covered PICA was noted to have recanalized on follow-up imaging 6 months later. Follow-up angiography was reported in 8 patients (the remaining 3 cases are awaiting follow-up) and demonstrated thrombosis of the aneurysm with patency of the PICA in all of them.

\section{Clinical and Radiographic Follow-Up}

Our practice protocol involves a clinical follow-up at 1 month, 3-6 months, and 12-18 months. We find that, in general, these time periods end up synching well with the stages of a patient's recovery and clinical progress. Additionally, they coincide with our imaging follow-up. Depending on the case and symptoms, later follow-up can be scheduled at 1- to 3-year intervals. Our imaging follow-up protocol consists of immediate postoperative control conventional angiography, then at 3-6 months and another session at 12-18 months. We also recommend MR angiography (MRA) at 12-18 months after treatment, and every 1-3 years subsequently, depending on the degree of aneurysm obliteration. We have settled on this follow-up paradigm based on both of the most common practices reported in current literature and from discussion with colleagues around the globe. We feel that, in a stable aneurysm, MRA is an adequate surrogate for conventional angiography, hence our switching to MRA after the 12- to 18-month follow-up angiography. However, the limitations of resolution of MRA make us feel that gold-standard angiography with maximal detail and resolution is still worthwhile for most patients during the first $12-18$ months, although this is certainly debatable and, in high-risk patients, we switch to MRA follow-up sooner. Patients undergoing SAC and flow-diverter placement are kept on a strict regimen of preand postoperative antiplatelet therapy, and dual therapy is maintained at least until the 3- to 6-month angiogram, after which aspirin is continued for life.

\section{Conclusions}

Given the evolving endovascular technologies over the last 2 decades in addition to high rates of complications and mortality associated with open surgery, endovascular therapy should be considered as the primary treatment

TABLE 1. Summary of large series (> 5 patients) on the use of flow diverters for PCFAs

\begin{tabular}{lclccc}
\hline \multicolumn{1}{c}{ Authors \& Year } & $\begin{array}{c}\text { No. of } \\
\text { PCFAs }\end{array}$ & $\begin{array}{c}\text { Flow Diverter } \\
\text { Device }\end{array}$ & $\begin{array}{c}\text { No. of Device-Related } \\
\text { Complications }\end{array}$ & $\begin{array}{c}\text { No. of } \\
\text { Deaths }\end{array}$ & $\begin{array}{c}\text { No. w/ Complete } \\
\text { Obliteration on Angiography }\end{array}$ \\
\hline Byrne et al., 2010 & 11 & Silk & 2 & 2 & NA \\
\hline Siddiqui et al., 2012 & 7 & PED (6), Silk (1) & 6 & 4 & 2 \\
\hline Monteith et al., 2014 & 7 & PED & 2 & 1 & 2 \\
\hline Munich et al., 2014 & 12 & PED & 3 & 1 & $9(75 \%)^{*}$ \\
\hline Natarajan et al., 2016 & 12 & PED & 1 & 0 & $12(100 \%)$ \\
\hline Bhogal et al., 2017 & 24 & PED, p64 & NA & 1 & $18(75 \%)$ \\
\hline
\end{tabular}

NA = not available.

* Data were not available for 2 patients. Of the 10 patients who underwent angiography, 9 patients (90\%) had complete occlusion. 
modality for PCFAs. For aneurysms that are not treatable by endovascular methods, microsurgical treatment should be considered. Flow diversion is a new endovascular method and can achieve excellent outcomes in carefully selected patients with PCFAs.

\section{References}

1. Aoki N, Sakai T: Rebleeding from intracranial dissecting aneurysm in the vertebral artery. Stroke 21:1628-1631, 1990

2. Bhogal P, Pérez MA, Ganslandt O, Bäzner H, Henkes H, Fischer S: Treatment of posterior circulation non-saccular aneurysms with flow diverters: a single-center experience and review of 56 patients. J Neurointerv Surg 9:471-481, 2017

3. Brinjikji W, Murad MH, Lanzino G, Cloft HJ, Kallmes DF: Endovascular treatment of intracranial aneurysms with flow diverters: a meta-analysis. Stroke 44:442-447, 2013

4. Byrne JV, Beltechi R, Yarnold JA, Birks J, Kamran M: Early experience in the treatment of intra-cranial aneurysms by endovascular flow diversion: a multicentre prospective study. PLoS One 5:5, 2010

5. Chalouhi N, Tjoumakaris S, Dumont AS, Gonzalez LF, Randazzo C, Starke RM, et al: Treatment of posterior circulation aneurysms with the Pipeline Embolization Device. Neurosurgery 72:883-889, 2013

6. Coert BA, Chang SD, Do HM, Marks MP, Steinberg GK: Surgical and endovascular management of symptomatic posterior circulation fusiform aneurysms. J Neurosurg 106:855-865, 2007

7. Day AL, Gaposchkin CG, Yu CJ, Rivet DJ, Dacey RG Jr: Spontaneous fusiform middle cerebral artery aneurysms: characteristics and a proposed mechanism of formation. $\mathbf{J}$ Neurosurg 99:228-240, 2003

8. Drake CG: Giant intracranial aneurysms: experience with surgical treatment in 174 patients. Clin Neurosurg 26:12-95, 1979

9. Drake CG, Peerless SJ: Giant fusiform intracranial aneurysms: review of 120 patients treated surgically from 1965 to 1992. J Neurosurg 87:141-162, 1997

10. Echiverri HC, Rubino FA, Gupta SR, Gujrati M: Fusiform aneurysm of the vertebrobasilar arterial system. Stroke 20:1741-1747, 1989

11. Fischer S, Perez MA, Kurre W, Albes G, Bäzner H, Henkes $\mathrm{H}$ : Pipeline Embolization Device for the treatment of intraand extracranial fusiform and dissecting aneurysms: initial experience and long-term follow-up. Neurosurgery 75:364374, 2014

12. Flemming KD, Wiebers DO, Brown RD Jr, Link MJ, Huston J III, McClelland RL, et al: The natural history of radiographically defined vertebrobasilar nonsaccular intracranial aneurysms. Cerebrovasc Dis 20:270-279, 2005

13. Flemming KD, Wiebers DO, Brown RD Jr, Link MJ, Nakatomi H, Huston J III, et al: Prospective risk of hemorrhage in patients with vertebrobasilar nonsaccular intracranial aneurysm. J Neurosurg 101:82-87, 2004

14. Gascou G, Lobotesis K, Brunel H, Machi P, Riquelme C, Eker O, et al: Extra-aneurysmal flow modification following Pipeline Embolization Device implantation: focus on regional branches, perforators, and the parent vessel. AJNR Am J Neuroradiol 36:725-731, 2015

15. Higashida RT, Smith W, Gress D, Urwin R, Dowd CF, Balousek PA, et al: Intravascular stent and endovascular coil placement for a ruptured fusiform aneurysm of the basilar artery. Case report and review of the literature. J Neurosurg 87:944-949, 1997

16. Kalani MY, Zabramski JM, Nakaji P, Spetzler RF: Bypass and flow reduction for complex basilar and vertebrobasilar junction aneurysms. Neurosurgery 72:763-776, 2013

17. Kulcsár Z, Ernemann U, Wetzel SG, Bock A, Goericke S,
Panagiotopoulos V, et al: High-profile flow diverter (Silk) implantation in the basilar artery: efficacy in the treatment of aneurysms and the role of the perforators. Stroke 41:16901696, 2010

18. Lall RR, Crobeddu E, Lanzino G, Cloft HJ, Kallmes DF: Acute branch occlusion after Pipeline embolization of intracranial aneurysms. J Clin Neurosci 21:668-672, 2014

19. Lawton MT, Abla AA, Rutledge WC, Benet A, Zador Z, Rayz VL, et al: Bypass surgery for the treatment of dolichoectatic basilar trunk aneurysms: a work in progress. Neurosurgery 79:83-99, 2016

20. Levitt MR, Park MS, Albuquerque FC, Moon K, Kalani MY, McDougall CG: Posterior inferior cerebellar artery patency after flow-diverting stent treatment. AJNR Am J Neuroradiol 37:487-489, 2016

21. Mangrum WI, Huston J III, Link MJ, Wiebers DO, McClelland RL, Christianson TJ, et al: Enlarging vertebrobasilar nonsaccular intracranial aneurysms: frequency, predictors, and clinical outcome of growth. J Neurosurg 102:72-79, 2005

22. Mazur MD, Kilburg C, Wang V, Taussky P: Pipeline Embolization Device for the treatment of vertebral artery aneurysms: the fate of covered branch vessels. J Neurointerv Surg 8:1041-1047, 2016

23. Mizutani T, Aruga T, Kirino T, Miki Y, Saito I, Tsuchida $\mathrm{T}$ : Recurrent subarachnoid hemorrhage from untreated ruptured vertebrobasilar dissecting aneurysms. Neurosurgery 36:905-913, 1995

24. Mizutani T, Miki Y, Kojima H, Suzuki H: Proposed classification of nonatherosclerotic cerebral fusiform and dissecting aneurysms. Neurosurgery 45:253-260, 1999

25. Monteith SJ, Tsimpas A, Dumont AS, Tjoumakaris S, Gonzalez LF, Rosenwasser RH, et al: Endovascular treatment of fusiform cerebral aneurysms with the Pipeline Embolization Device. J Neurosurg 120:945-954, 2014

26. Munich SA, Tan LA, Keigher KM, Chen M, Moftakhar R, Lopes DK: The Pipeline Embolization Device for the treatment of posterior circulation fusiform aneurysms: lessons learned at a single institution. J Neurosurg 121:1077-1084, 2014

27. Natarajan SK, Lin N, Sonig A, Rai AT, Carpenter JS, Levy EI, et al: The safety of Pipeline flow diversion in fusiform vertebrobasilar aneurysms: a consecutive case series with longer-term follow-up from a single US center. J Neurosurg 125:111-119, 2016

28. Phillips TJ, Wenderoth JD, Phatouros CC, Rice H, Singh TP, Devilliers L, et al: Safety of the Pipeline Embolization Device in treatment of posterior circulation aneurysms. AJNR Am J Neuroradiol 33:1225-1231, 2012

29. Raphaeli G, Collignon L, De Witte O, Lubicz B: Endovascular treatment of posterior circulation fusiform aneurysms: single-center experience in 31 patients. Neurosurgery 69:274-283, 2011

30. Sacho RH, Saliou G, Kostynskyy A, Menezes R, Tymianski M, Krings T, et al: Natural history and outcome after treatment of unruptured intradural fusiform aneurysms. Stroke 45:3251-3256, 2014

31. Serrone JC, Gozal YM, Grossman AW, Andaluz N, Abruzzo T, Zuccarello M, et al: Vertebrobasilar fusiform aneurysms. Neurosurg Clin N Am 25:471-484, 2014

32. Siddiqui AH, Abla AA, Kan P, Dumont TM, Jahshan S, Britz $\mathrm{GW}$, et al: Panacea or problem: flow diverters in the treatment of symptomatic large or giant fusiform vertebrobasilar aneurysms. J Neurosurg 116:1258-1266, 2012

33. Steinberg GK, Drake CG, Peerless SJ: Deliberate basilar or vertebral artery occlusion in the treatment of intracranial aneurysms. Immediate results and long-term outcome in 201 patients. J Neurosurg 79:161-173, 1993

34. Uda K, Murayama Y, Gobin YP, Duckwiler GR, Viñuela F: 
Endovascular treatment of basilar artery trunk aneurysms with Guglielmi detachable coils: clinical experience with 41 aneurysms in 39 patients. J Neurosurg 95:624-632, 2001

35. Wells HG: Intracranial aneurysm of the vertebral artery. Arch Neurol Psychiatry 7:311-320, 1922

36. Yeung TW, Lai V, Lau HY, Poon WL, Tan CB, Wong YC: Long-term outcome of endovascular reconstruction with the Pipeline Embolization Device in the management of unruptured dissecting aneurysms of the intracranial vertebral artery. J Neurosurg 116:882-887, 2012

\section{Disclosures}

Dr. Mocco reports that he is a consultant for Rebound Medical, EndoStream, Synchron, and Cerebrotech; has ownership in
Apama, The Stroke Project, EndoStream, Synchron, Cerebrotech, Neurvana, and NeuroTechnology Investors; and receives nonstudy-related support from Stryker Neurovascular, Penumbra, Medtronic, and MicroVention.

\section{Author Contributions}

Conception and design: Mocco, Awad, Mascitelli. Acquisition of data: Awad. Drafting the article: Awad, Mascitelli, Haroun. Critically revising the article: all authors.

\section{Correspondence}

J Mocco, Department of Neurological Surgery, Icahn School of Medicine at Mount Sinai, Mount Sinai Health System, 1468 Madison Ave., New York, NY 10029. email: j.mocco@ mountsinai.org. 